\title{
prefacel ACKNOWLEDGMENTS
}

This book will see daylight nearly in time to celebrate the fortieth anniversary of Food Not Bombs' very first meal. On March 26, 1981, its organizers dressed as self-styled hobos and held a Depression-era soup kitchen with donated castoffs outside the Bank of Boston's stockholders meeting. It was pure political theatre. (In 1981, the sight of homeless people crowding American streets remained an anachronistic novelty. If you can imagine that.) The spectacle was meant to illustrate the epic financial crash augured by the bank's investment in nuclear energy and militarism. Nobody quite guessed the soup line would grow into an international gastronomic conspiracy.

Much has changed over the past forty years - and Food Not Bombs with it. In retrospect, they weren't wholly wrong about the depression: the twin tides of globalization and neoliberalism have borne cascading, interwoven crises that have seen wealth pool among the super-rich while inequality, hunger, and homelessness grow starker by the year in many cities. That great transformation has also been the crucible from which emerged a global movement of anarchist soup kitchens.

This book tells a tale of its forging, and of the landscapes from which its raw materials precipitate. It is a work of slow scholarship, in some ways dating back to my earliest days with FNB, when both the movement and I were a spry twenty-five years old. Since then, I have watched both Food Not Bombs and the urban crises that stoke it deepen and evolve. This book aims to capture something of that long arc. I hope it contains a usefulalbeit partial - map for advocates, radicals, and scholars to navigate some of the next forty years. 
That future is singularly hazy right now, amid recession, pandemic, and political unrest unprecedented in recent memory. We cannot know how they will transform our world. Some of the world-class business districts described in this book, for example, have been evacuated for now - by those who can afford it. Who can say when or how they will return? Yet these crises exacerbate the underlying conditions of our era in ways that seem familiar to anyone who's spent time with FNB: supply chains are disrupted and food languishes in the fields while unemployed Americans queue for blocks at understocked food banks, yet the contradiction between squandered food and hunger has always been at FNB's heart; the COVID-19 pandemic devastates some neighborhoods and largely spares others, revealing older urban divisions that are the impetus for FNB's mutual aid; and urban uprisings proliferate globally at neverbefore-seen speed, emerging from the kinds of everyday structural violence, and the dynamo of police repression and grassroots resistance, that give rise to nonviolent insurrections like Food Not Bombs. (As I type this, some of my FNB collaborators in Seattle have lent their bodies to a motley, mutinous coalition, led by the Black Lives Matter movement, to peacefully occupy a six-block "autonomous zone" against police brutality and urban disenfranchisement. Within the zone-as elsewhere around the world - FNB and other activists continue to ply the skills of mutual aid and civil disobedience to share food freely, despite the pandemic.) The story of Food Not Bombs might, I hope, teach us much about the world that emerges from this moment.

Countless people have made that story, and this book, possible. Above all, I owe the book to the caring labor of the Food Not Bombs collaborators alongside whom I have volunteered. They have been friends, critics, and peers. And among the wider political landscapes that FNB inhabits, I am grateful to Victoria Law, Natalie Novak, Tim Harris, Rachael Myers, Anitra Freeman, Wes Browning, Keith McHenry, Simon Stephens, Graham Pruss, Kelly Whitmore, Spike Chiappalone, and particularly Jeff Juris, whose advice resonates through this book and whose passing is a loss to us all. For institutional support I thank Deakin University, the Alfred Deakin Institute for Citizenship and Globalisation, the University of Washington's Department of Comparative History of Ideas, the Harry Bridges Center for Labor Studies, the Simpson Center for the Humanities, and the Nancy Bell Evans Center on Nonprofits and Philanthropy. For helping me incubate these thoughts, I thank Ann Anagnost, Miriam Kahn, Celia Lowe, Phillip Thurtle, Maggie Dickinson, Patricia Lopez, Katie Gillespie, Victoria Lawson, Sarah Elwood, Teresa Mares, Trang Ta, Da- 
vid Spataro, Alex Vitale, Jill Friedberg, Trevor Griffey, Robertson Allen, Matt Hale, Amir Sheikh, Mariana Markova, Tim Neale, Tanya King, Victoria Stead, Roland Kapferer, Louise Johnson, Melinda Hinkson, Emma Kowal, Eben Kirksey, Bree Carlton, Jen Moore, Tamara Myers, Ryan Burt, Emily Clark, Erin Clowes, Jed Murr, Alice Pedersen, Kyle Croft, Beth Scholler, Heather Rastovac, Jessica D’Amour, Shealeigh Heindel, Ryder Richardson, Melissa Espinoza, Monica Chahary, and particularly Danny Hoffman. And my deepest gratitude is for the journey of personal becoming behind any kind of research. Thanks Laurie Penny, Jessie Kindig, Meg Murphy, Amy Peloff, Olivia Little, Noora El Shaari, Violeta Hernandez, Jill Schaffner, Taryn Dorsey, Sabrina Chap, Courtney Cecale, Risa Cromer, Lilly Frank, Lauren Lichty, Kathryn Tafra, Lily So Too, Francisco Iturbide, Peter Donahue, Joe Thompson, Jake Warga, Raven Healing, Kris Edin, Kevin "Doc" Dockery, Ash Martin-Bumpus, Amalia Davalos, Cale Wilcox, David O'Bright, Paul Ohnemus, Erin Ohnemus, Elizabeth Rard, David Wallace, Nathan Shields, Shauna "Cutter" Greene, Laura Palachuk, Kawan Baxter, Mary Holly, Ani Borua, Kevin “Irish” Kelly, Koa Kaelepulu, Corri Chase, Oats Habercorn, Wilson Shook, Eric Wirkman, Ryan Bartek, Garlicana Farms, and Annabelle Crosbie, among others. And for teaching me, in their ways, to read, care, play, endure, and help, I can thank Marilyn Boarder, Neil Blacker, and Michael Giles. These people and many more have helped make this book what it is. The errors are mine alone. But whatever it may achieve belongs to all of us. 

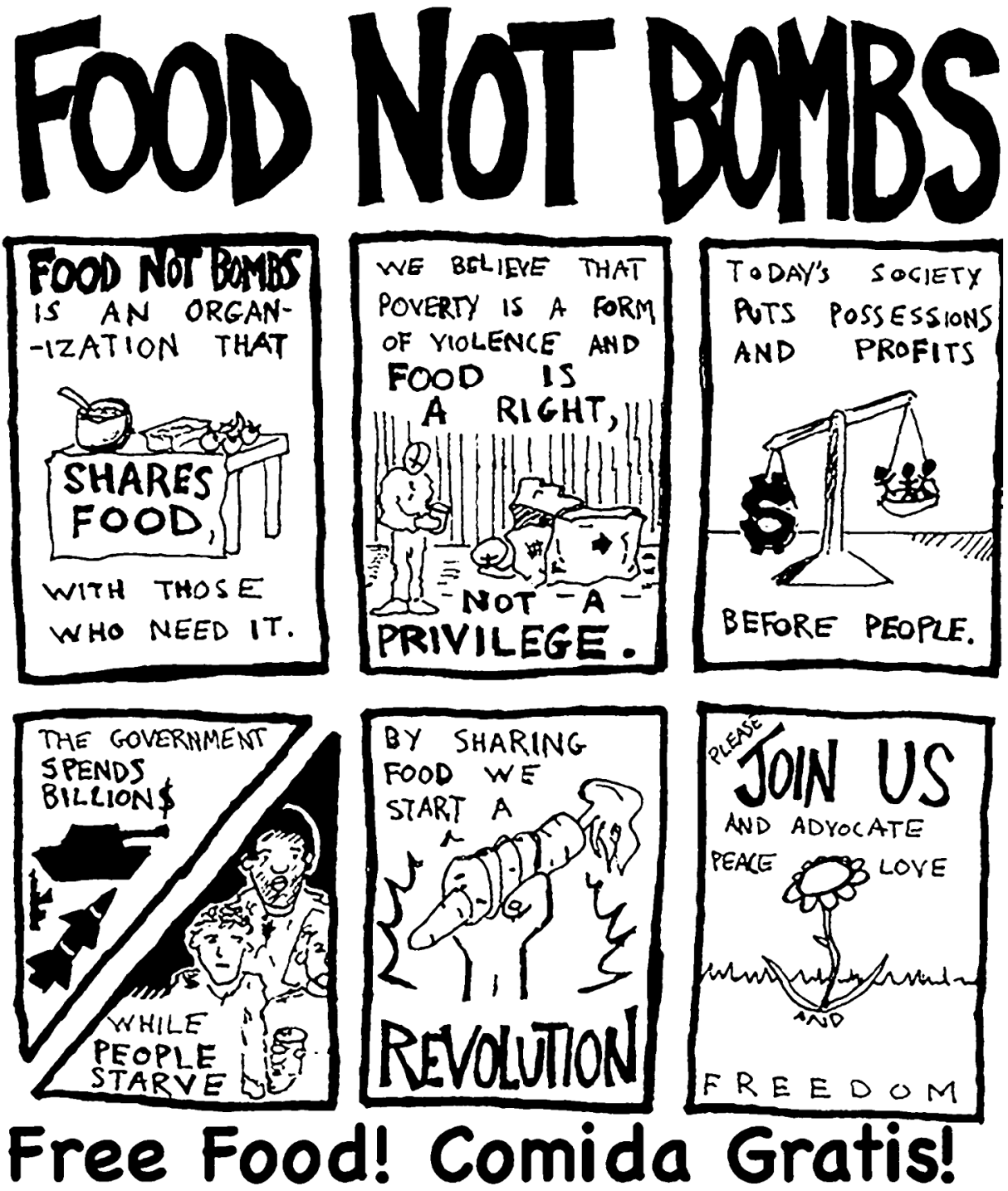

Free Food! Comida Gratis!

\section{Every Sunday @ 2:30PM,}

